\title{
Study on the correlation between Vitamin D and HbA1c in type 2 diabetes mellitus
}

\author{
Ponnambalam A. ${ }^{1}$, Arun M. ${ }^{2 *}$, Prabhu G. ${ }^{3}$ \\ DOI: https://doi.org/10.17511/ijmrr.2021.i04.03 \\ 1 Ponnambalam A, Associate Professor, Department of General Medicine, SVMCH\&RC, Pondicherry, India. \\ 2* Arun M, Assistant Professor, Department of General Medicine, SVMCH\&RC, Pondicherry, India. \\ 3 Prabhu G., Professor, Department of General Medicine, SVMCH\&RC, Pondicherry, India.
}

Background: Type 2 diabetes mellitus (DM) is associated with increased morbidity and mortality due to the development of complications, especially due to poor glycemic control. Besides its role in calcium homeostasis, Vitamin $D$ has been involved in the pathophysiology as well as glycemic control of type 2 DM. Methods: 100 patients diagnosed with type 2 DM were included. Vitamin D levels along with glycosylated haemoglobin were measured in all the individuals. Results: Vitamin $D$ deficiency was observed in $48 \%$ of the patients. Vitamin D levels were not associated with markers of glycemic control (HbA1c). Conclusions: Hypovitaminosis D was observed nearly in half of the patients with type 2 diabetes, suggesting a potential for vitamin D supplementation in type 2 DM patients.

Keywords: Diabetes mellitus, glycated haemoglobin, glycemic control, Vitamin D

Corresponding Author

Arun M, Assistant Professor, Department of General Medicine, SVMCH\&RC, Pondicherry, India. Email: arjun.manivannan2018@gmail.com
How to Cite this Article

Ponnambalam A, Arun M, Prabhu G. Study on the correlation between Vitamin D and HbA1c in type 2 diabetes mellitus. Int J Med Res Rev. 2021;9(4):219224.

Available From

https://ijmrr.medresearch.in/index.php/ijmrr/article/ view/1310
To Browse

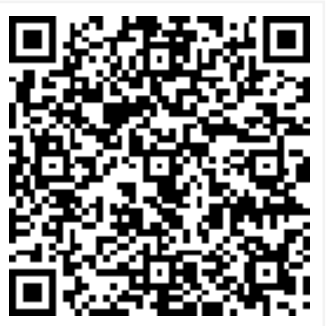

Manuscript Received 2021-05-21

Conflict of Interest No
Review Round 1 2021-06-12

Funding
Review Round 2 2021-06-25

Ethical Approval Yes
Review Round 3 2021-07-10

Plagiarism X-checker $8 \%$
Accepted 2021-07-28

Note

(c) 2021 by Ponnambalam A, Arun M, Prabhu G. and Published by Siddharth Health Research and Social Welfare Society. This is an Open Access article licensed under a Creative Commons Attribution 4.0 International License https://creativecommons.org/licenses/by/4.0/ unported [CC BY 4.0]. 


\section{Introduction}

Type 2 DM is associated with several macrovascular and microvascular complications which lead to high morbidity and mortality. It's more important to achieve good glycemic control which helps in reducing the complications associated with DM. To achieve good glycemic control and to decrease the complications of DM, diabetes patients should follow strict dietary control, regular exercise, adherence to medication, and regular monitoring of glucose levels. [1]. As worldwide commonly used markers for monitoring glycemic control include fasting blood sugar (FBS), postprandial blood sugar (PPBS), glycosylated haemoglobin (HbA1c).

In addition to these markers, fructosamine, glycated albumin, and 1,5-anhydroglucitol are also used as markers of glycemic control. [2]. Vitamin D is a fatsoluble vitamin that is synthesized from 7-dehydrocholesterol in the skin upon exposure to ultraviolet $B$ rays of sunlight. 1,25-dihydroxycholecalciferol which is the active form of Vitamin D plays an important role in the maintenance of calcium homeostasis by binding to its receptors on its target tissues which include bone, kidney and intestine. In addition to its role in maintaining bone health, Vitamin $D$ has several important extra skeletal biochemical functions in the body, including its role in type 1 and type 2 DM. [3]. Vitamin D was shown to be associated with type 2 DM through its effects on insulin secretion, insulin sensitivity and systemic inflammation, which are the three major mechanisms underlying the development of type 2 DM. [4].

Data from cross-sectional as well as longitudinal studies suggest that Vitamin $D$ deficiency has a causal role in type 2 DM. [5,6]. Moreover, a high prevalence of Vitamin $D$ deficiency in diabetes patients has also been reported earlier. [7-9]. Owing to its effects on insulin sensitivity, Vitamin $D$ is suggested to have a presumptive role in glycemic control. However, studies exploring the relationship between Vitamin $D$ levels and glycemic control in type 2 diabetes patients reported varied findings. [10-12]. In this background, we were interested to evaluate the association between serum Vitamin $D$ levels and $\mathrm{Hba} 1 \mathrm{Cl}$ in patients with type $2 \mathrm{DM}$.

\section{Material and Methods}

The study was conducted during the period from Jan 2019 to Dec 2019 in SVMCH\&RC -Pondicherry.
The sample size was 100patients who attending to the department of General Medicine and diabetology OPD. T2DM was diagnosed as per the American Diabetes Association criteria. [13]. Patients with T2DM (old/newly diagnosed) above the age of 18 , both gender and willingness to participate were included in the study.

Patients with other forms of DM (type1 diabetes), history of smoking, alcoholism, thyroid disorders, cardiovascular disease, cerebrovascular disease, chronic kidney disease, malignancy, acute and chronic inflammatory diseases, patients who are on insulin, corticosteroids and Vitamin D or calcium supplementation, pregnant and lactating women and those not willing to participate were excluded from the study.

Vitamin D deficiency is defined as 25-hydroxyvitamin D levels more than $20 \mathrm{ng} / \mathrm{mL}$ (Vitamin D non-deficient) and patients with Vitamin $\mathrm{D} \leq 20 \mathrm{ng} / \mathrm{mL}$ (Vitamin $\mathrm{D}$ deficient). The sample size was calculated based on the data obtained from previous studies using the $\mathrm{n}$ - Master software version developed by the Department of Biostatistics, Christian Medical College, and Vellore. The study was approved by the institutional Ethics Committee and scientific research committee.

Sample collection: All patients included in the study were subjected to detailed history and physical examination as per proforma followed. Five $\mathrm{mL}$ of fasting venous blood samples were collected from all the individuals after informed consent. The samples were separated and stored at $-80^{\circ} \mathrm{C}$ until further analysis. HbA1c levels were assayed on Bio-Rad D10 system by high-performance liquid chromatography-based ion-exchange chromatography as per the National Glycohemoglobin Standardization Program standardized to the Diabetes Control and Complications Trial. [14]. Vitamin D was analyzed by chemiluminescence immunoassay using Beckman coulter access 2 auto analyzer. Vitamin D levels were measured on the same day of sample collection.

Statistical analysis: The association between the variables studied was analyzed using Pearson or Spearman correlation analysis depending on the distribution of data. $P<0.05$ was considered statistically significant. All statistical analyses were performed using Microsoft Excel spreadsheets and Statistical Package for Social Sciences (SPSS Inc., Chicago, IL, USA) for windows version 16.0. 


\section{Results}

Table 1 Age/sex distribution of the study population

\begin{tabular}{|l|l|l|l|}
\hline \multirow{2}{*}{ Age } & \multicolumn{2}{|c|}{ Sex } & \multirow{2}{*}{ Total } \\
\cline { 2 - 3 } & Male & Female & \\
\hline $18-30$ & 05 & 03 & 08 \\
\hline $31-40$ & 12 & 07 & 19 \\
\hline $41-50$ & 20 & 09 & 29 \\
\hline $51-60$ & 14 & 10 & 24 \\
\hline$>60$ & 11 & 09 & 20 \\
\hline Total & 62 & 38 & 100 \\
\hline
\end{tabular}

In our study, we had the youngest patient with $18 y e a r s$ and the oldest patient with 78years. In the present study, we had maximum patients in the age group between 41 to 50 years as similar to various other studies. In our study male was $68 \%$ with females were $38 \%$.

Table 2 HbA1c distribution of the study population

\begin{tabular}{|l|l|l|l|}
\hline \multirow{2}{*}{ HbA1c } & \multicolumn{2}{c|}{ Sex } & \multirow{2}{*}{ Total } \\
\cline { 2 - 3 } & Male & Female & \\
\hline$<6.5$ & & - & - \\
\hline $6.5-7.0$ & 10 & 06 & 16 \\
\hline $7.1-8.0$ & 32 & 20 & 52 \\
\hline$>8.0$ & 20 & 12 & 32 \\
\hline Total & 62 & 38 & 100 \\
\hline
\end{tabular}

In the present study, we estimated $\mathrm{HbA1c}$ for the identification of glycemic control which is to be identified as the most appropriate method. We identified a wide range with the lowest as $6.6 \%$ to $12.8 \%$ being the highest value. A maximum of $52 \%$ was in the range of 7.1 to $8 \%$ which is identified as fair control.

Table 3 (a) Distribution of vitamin D levels among the study population

\begin{tabular}{|l|l|l|}
\hline \multicolumn{1}{|c|}{ Vitamin D $(\mathrm{ng} / \mathrm{ml})$} & No of patients & Percentage (\%) \\
\hline$\leq 20$ & 48 & 48 \\
\hline$>20$ & 52 & 52 \\
\hline Total & 100 & 100 \\
\hline
\end{tabular}

Table 3(b) Vitamin D levels among the study population

\begin{tabular}{|l|l|l|}
\hline \multicolumn{1}{|c|}{ Vitamin D $(\mathrm{ng} / \mathrm{ml})$} & \multicolumn{1}{|c|}{ Male $(\mathrm{n}=68)$} & \multicolumn{1}{c|}{ Female $(\mathrm{n}=\mathbf{3 2})$} \\
\hline$\leq 20$ & $18.24 \pm 6.4$ & $18.97 \pm 6.9$ \\
\hline$>20$ & $23.68 \pm 8.77$ & $22.97 \pm 8.2$ \\
\hline
\end{tabular}

In the present study, we estimated vitamin D levels in all subjects and categorization was done as $<20$ and more than $20 \mathrm{ng} / \mathrm{dl} .48 \%$ of patients had vitamin D levels below 20ng/dl.
Table 4 Vitamin D vs. HbA1c (with P-value)

\begin{tabular}{|l|l|l|l|l|}
\hline \multirow{2}{*}{ HbA1c } & \multirow{2}{*}{ Mean } & \multicolumn{2}{|c|}{ Vitamin D (ng/ml) } & \multirow{2}{*}{ P-value } \\
\cline { 3 - 4 } & & $\leq 20$ & $>20$ & \\
\hline$\leq 6.5$ & & & - & - \\
\hline $6.6-7.0$ & $6.89 \pm 1.01$ & $18.12 \pm 5.4$ & $21.42 \pm 6.6$ & $<0.014276$ \\
\hline $7.1-8.0$ & $7.49 \pm 1.27$ & $18.79 \pm 5.7$ & $22.64 \pm 7.64$ & $<0.04287$ \\
\hline$>8.0$ & $8.24 \pm 1.92$ & $18.48 \pm 5.4$ & $22.97 \pm 8.4$ & $<0.05945$ \\
\hline
\end{tabular}

In the present study, we compared the values of $\mathrm{HbA1C}$ with vitamin D levels where we did not notice much difference with the mean of individual categories.

\section{Discussion}

One of the important emerging nutritional risk factors recognized for the development of insulin resistance (IR) and T2DM is the deficiency of vitamin D. Also it has been proposed to be associated with worsening of glycemic control and progression of complications among T2DM individuals. [15]. Despite adequate sunlight exposure throughout the year, several studies documented deficiency of vitamin $D$ as the most prevalent finding among Indians [16].

However, recently the shreds of evidence have shown hypovitaminosis $D$ as a risk factor in the causation of various non-communicable, metabolic disorders. Numerous research studies documented the association of insufficiency or deficiency of Vitamin D with T2DM. Beneficial effects of the administration of vitamin $D$ in improving insulin sensitivity among diabetics are also reported. The exact mechanism by which VDD may affect glycemic control is not fully understood; however, potential pathways have been suggested which involve pancreatic beta-cell dysfunction, reduced insulin sensitivity, and inflammation.

But whether supplementation of vitamin D prevents the development of T2DM and its complications is not confirmed due to inconsistent results from clinical trials. Our study aimed to see the association between glycemic status and vitamin D levels to establish its relationship. In the present study, serum Vitamin D levels were measured in 100 patients diagnosed with type 2 DM. It was found that $48 \%$ of the patients are Vitamin D deficient and $52 \%$ had normal levels of more than 20ng/dl. The association between $\mathrm{HbA} 1 \mathrm{c}$ and $25(\mathrm{OH}) \mathrm{D}$ is controversial. The relationship of Vitamin $D$ with measures of glycemic control such as $\mathrm{HbA} 1 \mathrm{c}$ could not be confirmed in the population studied. 
We did not find a statically significant correlation between $\mathrm{HbA} 1 \mathrm{C}$ and $25(\mathrm{OH}) \mathrm{D}$, similar to other previously published studies. [17,18,19,20,21,22]. However glycemic control was not associated with vitamin $D$ when we controlled for confounding factors, as verified by Luo et al. and Al-Shoumer et al. $[23,24]$. In a study done by Figenia KostoglouAthanassiou et al observed, lower 25(OH) D3 levels were observed in diabetes mellitus type 2 patients than in non-diabetic controls. Vitamin D was shown to be associated with beta-cell function and insulin sensitivity in individuals at risk for DM and thus might play a role in the pathogenesis of type $2 \mathrm{DM}$. [25]. However, in a recent multicenter, randomized control trial [26]. It was reported that supplementation with $4000 \mathrm{IU} /$ day of Vitamin D3 increased Vitamin $D$ levels but did not lower the risk of DM compared to placebo after a median follow-up of 2.5 years. Since the physiological role of Vitamin $D$ in pancreatic beta-cell function and insulin sensitivity is well appreciated, and considering that almost $48 \%$ of the diabetes patients in the present study are Vitamin D deficient, it is suggested that Vitamin $D$ levels are measured in these patients to identify hypovitaminosis D. Although it is not clear whether Vitamin $D$ supplementation improves glycemic status, improvement in Vitamin D levels in diabetes patients might help in improving the overall health of the individuals along with an increase in Vitamin D levels. Simple measures such as dietary changes and lifestyle modifications along with Vitamin $D$ supplementation may help in achieving normal Vitamin $D$ levels in DM patients. All the measurements in the diabetes patients in the present study were done at a single time point which forms a limitation of the present study. Considering the beneficial role played by Vitamin $D$ on glucose homeostasis, the relationship between Vitamin $D$ levels and glycemic control needs to be explored in further large, well-controlled studies with higher population and multicentric.

\section{Conclusion}

In conclusion, we have identified a negative correlation concerning vitamin $D$ levels when compared with HbA1c statically. Since the physiological role of Vitamin $D$ in pancreatic betacell function and insulin sensitivity is well appreciated, and considering that almost $50 \%$ of the diabetes patients in the present study are Vitamin D deficient, it is suggested that Vitamin D levels improve the glycemic status in type 2 diabetes mellitus patients.

\section{What does the study add to existing knowledge?}

This study justifies an acute need for populationbased screening of a large sample-sized population to prove the role of vitamin $D$ in every stage, from prevention to management.

\section{Author contributions}

AP, MA collected the data, conducted this study, did data analysis. GP did manuscript drafting. All authors were involved in revising and approved the final version of the manuscript.

\section{Reference}

01. Ahmad NS, Islahudin F, Paraidathathu T. Factors associated with good glycemic control among patients with type 2 diabetes mellitus. J Diabetes Investig. 2014;5(5)563-9. doi: 10.1111/jdi.12175 [Crossref][PubMed][Google Scholar]

02. Lee JE. Alternative biomarkers for assessing glycemic control in diabetes- fructosamine, glycated albumin, and 1,5-anhydroglucitol. Ann Pediatr Endocrinol Metab. 2015 Jun;20(2)74-8. doi: 10.6065/apem.2015.20.2.74 [Crossref][PubMed] [Google Scholar]

03. Griz LH, Bandeira F, Gabbay MA, Dib SA, Carvalho EF. Vitamin $D$ and diabetes mellitus: an update 2013. Arq Bras Endocrinol Metabol. 2014 Feb;58(1)1-8. doi: 10.1590/0004-2730000002535 [Crossref][PubMed][Google Scholar]

04. Harinarayan CV. Vitamin D and diabetes mellitus. Hormones (Athens). 2014 AprJun;13(2)163-81. doi: 10.1007/BF03401332 [Crossref][PubMed][Google Scholar]

05. Scragg R, Sowers M, Bell C. Third National Health and Nutrition Examination Survey, Serum 25-hydroxyvitamin $D$, diabetes, and ethnicity in the Third National Health and Nutrition Examination Survey. Diabetes Care. 2004 Dec;27(12)2813-8. doi: $\quad 10.2337 /$ diacare.27.12.2813 [Crossref] [PubMed][Google Scholar]

06. Pittas AG, Dawson-Hughes B, Li T, Van Dam RM, Willett WC, Manson JE, Hu FB. Vitamin D and calcium intake in relation to type 2 diabetes in women. Diabetes Care. 2006 Mar;29(3)650-6. doi: 10.2337/diacare.29.03.06.dc05-1961 [Crossref] [PubMed][Google Scholar] 
07. Nwosu BU, Maranda L. The effects of vitamin D supplementation on hepatic dysfunction, vitamin D status, and glycemic control in children and adolescents with vitamin D deficiency and either type 1 or type 2 diabetes mellitus. PLoS One. 2014;9(6)e99646. doi: 10.1371/journal.pone. 0099646 [Crossref][PubMed][Google Scholar]

08. Rolim MC, Santos BM, Conceição G, Rocha PN. Relationship between vitamin D status, glycemic control and cardiovascular risk factors in Brazilians with type 2 diabetes mellitus. Diabetol Metab Syndr. 2016 Nov 16;8;77. doi: 10.1186/s13098-016-01887 [Crossref][PubMed][Google Scholar]

09. Bayani MA, Akbari R, Banasaz B, Saeedi F. Status of Vitamin-D in diabetic patients. Caspian J Intern Med. 2014 Winter;5(1)40-2. [Crossref] [PubMed][Google Scholar]

10. Kostoglou-Athanassiou I, Athanassiou $P$, Gkountouvas A, Kaldrymides P. Vitamin D and glycemic control in diabetes mellitus type 2. Ther Adv Endocrinol Metab. 2013 Aug;4(4)122-8. doi: 10.1177/2042018813501189 [Crossref][PubMed] [Google Scholar]

11. Olt S. Relationship between vitamin $D$ and glycemic control in patients with type 2 diabetes mellitus. Int J Clin Exp Med. 2015;8(10)19180-3. [Crossref][PubMed][Google Scholar]

12. Perez-Diaz I, Sebastian-Barajas G, HernandezFlores ZG, Rivera-Moscoso R, Osorio-Landa HK, Flores-Rebollar $A$. The impact of vitamin $D$ levels on glycemic control and bone mineral density in postmenopausal women with type 2 diabetes. J Endocrinol Invest. $2015 \mathrm{Dec} ; 38(12) 1365-72$. doi: 10.1007/s40618-015-0394-4 [Crossref][PubMed] [Google Scholar]

13. American Diabetes Association. 2 Classification and Diagnosis of Diabetes. Diabetes Care. 2016 Jan;39 Suppl 1;S13-22. doi: 10.2337/dc16-S005 [Crossref][PubMed][Google Scholar]

14. The relationship of glycemic exposure (HbA1c) to the risk of development and progression of retinopathy in the diabetes control and complications trial. Diabetes. 1995 Aug;44(8)96883. [Crossref][PubMed][Google Scholar]

15. Brahmkshatriya PP, Mehta AA, Saboo BD, Goyal RK. Characteristics and Prevalence of Latent Autoimmune Diabetes in Adults (LADA). ISRN Pharmacol. 2012;580202. doi: 10.5402/2012/ 580202 [Crossref][PubMed][Google Scholar]
16. Mohan V, Sandeep S, Deepa R, Shah B, Varghese $C$. Epidemiology of type 2 diabetes- Indian scenario. Indian J Med Res. 2007 Mar;125(3)21730. [Crossref][PubMed][Google Scholar]

17. Targher G, Bertolini L, Padovani R, Zenari L, Scala L, Cigolini M, Arcaro G. Serum 25hydroxyvitamin D3 concentrations and carotid artery intima-media thickness among type 2 diabetic patients. Clin Endocrinol (Oxf). 2006 Nov;65(5)593-7. doi: 10.1111/j.13652265.2006.02633.x [Crossref][PubMed][Google Scholar]

18. Bellan M, Guzzaloni G, Rinaldi M, Merlotti E, Ferrari C, Tagliaferri A, et al. Altered glucose metabolism rather than naive type 2 diabetes mellitus (T2DM) is related to vitamin D status in severe obesity. Cardiovasc Diabetol. 2014 Mar $11 ; 13 ; 57 . \quad$ doi: 10.1186/1475-2840-13-57 [Crossref][PubMed][Google Scholar]

19. Kositsawat J, Freeman VL, Gerber BS, Geraci S. Association of $A 1 C$ levels with vitamin $D$ status in US adults- data from the National Health and Nutrition Examination Survey. Diabetes Care. 2010 Jun;33(6)1236-8. doi: 10.2337/dc09-2150 [Crossref][PubMed][Google Scholar]

20. Yu JR, Lee SA, Lee JG, Seong GM, Ko SJ, Koh G, et al. Serum vitamin $d$ status and its relationship to metabolic parameters in patients with type 2 diabetes mellitus. Chonnam Med J. 2012 Aug;48(2)108-15. doi: 10.4068/cmj.2012.48.2.108 [Crossref][PubMed][Google Scholar]

21. Al-Timimi DJ, Ali AF. Serum 25(OH) D in Diabetes Mellitus Type 2- Relation to Glycaemic Control. J Clin Diagn Res. 2013 Dec;7(12)2686-8. doi: $10.7860 / J C D R / 2013 / 6712.3733$ [Crossref] [PubMed][Google Scholar]

22. Manickam B, Neagu V, Kukreja S C, Barengolts E. Relationship between glycated hemoglobin and circulating 25-hydroxyvitamin D concentration in African American and Caucasian American men. Endocrine practice 19;1(2013)73-80. [Crossref] [PubMed][Google Scholar]

23. Luo C, Wong J, Brown M, Hooper M, Molyneaux $L$, Yue DK. Hypovitaminosis $D$ in Chinese type 2 diabetes- lack of impact on clinical metabolic status and biomarkers of cellular inflammation. Diab Vasc Dis Res. 2009 Jul;6(3)194-9. doi: 10.1177/1479164109337974 [Crossref][PubMed] [Google Scholar] 
24. Al-Shoumer KA, Al-Asoosi AA, Ali AH, Nair VS. Does insulin resistance in type 2 diabetes alter vitamin D status?. Prim Care Diabetes. 2013 Dec;7(4)283-7. doi: 10.1016/j.pcd.2013.04.008 [Crossref][PubMed][Google Scholar]

25. Kayaniyil S, Vieth R, Retnakaran R, Knight JA, Qi $Y$, Gerstein HC, et al. Association of vitamin D with insulin resistance and beta-cell dysfunction in subjects at risk for type 2 diabetes. Diabetes Care. 2010 Jun;33(6)1379-81. doi: 10.2337/dc09-2321 [Crossref][PubMed][Google Scholar]
26. Pittas AG, Dawson-Hughes $B$, Sheehan $P$, Ware $\mathrm{JH}$, Knowler WC, Aroda VR, et al. Vitamin D Supplementation and Prevention of Type 2 Diabetes. N Engl J Med. 2019 Aug 8;381(6)520-530. doi: 10.1056/NEJMoa1900906 [Crossref][PubMed] [Google Scholar] 